\title{
ME AND MY FLYING SAUCER
}

\section{A cosmic ride.}

\section{BY IAN WATSON}

$\mathrm{F}$ ellow people, this is probably your first ever sight of a genuine and altogether shimmering flying saucer! All those thousands of books about close encounters, abductions by aliens, things seen in the sky and in cornfields, are complete cow pies. Am I cleared for landing? I have something on board you'll be glad to see. Namely your four marooned Martian astronauts, sound in wind and limb. Juno, Jim, Chuck and Barbara won't suffocate on Mars on account of their ascent engine failing.

I couldn't possibly let J, J, C and B stifle in their tin can, even if this exposes my UFO to becoming an identified flying object. I could have clandestinely dumped the four of them anywhere hospitable in the world, near some highway, but that might have led to personal problems for the four, such as conspiracy theories, or getting disappeared. So I chose a public approach - though at the same time still fairly anonymous, like a caped crusader plus mask. My passengers haven't set eyes on me. For all they know, I might be an AAI, an alien AI.

$\mathrm{Oh}$, and I shan't be hanging around for long, an inch above the landing strip, so don't bother breaking out Château Rohypnol or dozed-up 7 Up on my account. As soon as the heroic quartet are safely on the ground, I'll be buzzing off promptly. And don't bother chasing me with those jets. I can do Mach 100 without batting an eyelid. Plus: cloak of invisibility. Just keep well back from this saucer, as you've no idea what energies it deploys. That includes your fire engines and ambulances with SWAT teams on board.

Your Mars quartet left their bags of rocks and dust back on the red planet; I didn't want mess in my hold. Oops, sorry, people, if I seem to be patronizing the brave quartet who took four months to get to Mars, whereas I brought them back in four hours, but it does take even little me several days to get to Neptune; I have limitations. As do fairly featureless blue Neptune and extremely chilly Triton: $-235^{\circ} \mathrm{C}$.

Why spend several days going to Triton? Why, to patrol the Far Frontier! Admittedly, there's an even farther frontier out in the Kuiper belt, not to mention the Oort cloud beyond, but... I confide nothing about refuelling my power system. Get going now, bold astronauts, out of the hold with you!

And of course the orbit of Neptune implies a very large sphere of mostly empty

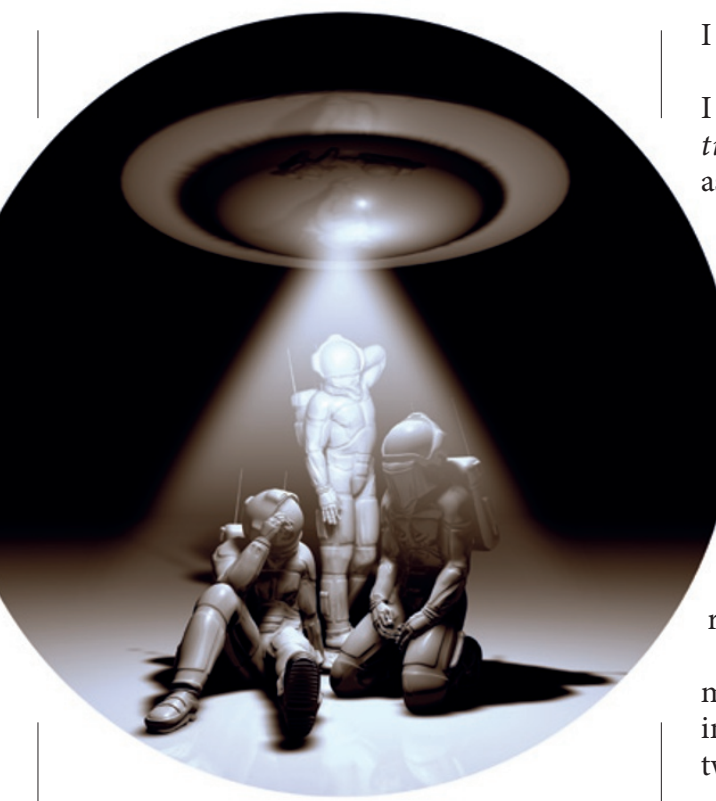

I shouldn't have said that.

As the mini-globe hovered before me, I put my hand upon it tentatively. Tingle tingle tingle. The gizmo read me and assessed: highly intelligent, atheist, ingenious, obsessional, dedicated, responsible, loves solitude, bold but not rash, et cetera ... I cottoned on instantly.

Evidently here was a very compact von Neumann first-contact gizmo. If you don't know what a vNfc gizmo is, you may as well stop listening. I guess the vNfc gizmo could have communicated with me efficiently in Korean, if I happened to be Korean. Although not Koranian - atheism seemed highly regarded in the aptitude test.

Proposal: would I accept to be the intermediary between Homo sap sap (so brainy, in our opinion, that we named ourselves twice) and the Outside intelligences?

Did Darwin go to the Galapagos Islands? Enough said.

space, but I'm not heading way out to gape at stars or to view the Sun as a very bright spot.

If you're already trying to do voice print recognition, just in case you strike lucky: waste of time. This is a synthvoice, although totally naturalistic.

Ah, Juno, I see you're outside. Skedaddle, lady! Don't make such a meal of it. You aren't that heavy on Earth.

How come I have an authentic flying saucer? I've been wondering whether to say, as this seems such a wet dream, pardon, such a fantasy, for a young geek like me.

It all began when I took a bit of tech of my own devising to a park at dusk. Don't jump to the conclusion that this might be a 4-qubit iPhone. I tapped in a very long number, nothing to do with $p i$, and I got a surprisingly swift response in the form of a glowing little globe rising lazily like a luminous golf ball and drifting towards me. I guess I happened to be in the right place, unless the rest of the world and the ocean depths are littered with globes imitating golf balls.

This does rather suggest, don't you think, that the earliest arrivals on our world from the Outside postdate our fourteenth century, although I suppose earlier arrivals might have masqueraded as fruits or nuts...

Now you, Chuck, stop your loitering.
Follow Futures: @ @NatureFutures

$f$ go.nature.com/mtoodm

\section{$\rightarrow$ NATURE.COM} All the way home I was gradually increasing the grav in the hold to re-accustom you, oops, maybe
Ah, Jim, I was wondering when. Lug your legs after Juno and Chuck. Bye-bye.

Basically my duties are to keep watch and transmit by the Outsider way - bet you'd like to know what that is - summaries of significant up-to-date Earth news. Likelihood of nuclear war or other global catastrophes, breakthroughs in nanotech or a star-drive. And no, I don't use tachyons to transmit. But I like the idea that the cosmos is non-causal, deep down; could that be a clue?

And then there was one... Come along now, Barbara. One small step for a lady mission commander. You know you can do it.

You aren't going to leave? Do you imagine you'll stall me here till someone fires a big net of green kryptonite over my UFO?

The ingratitude!

I swear I'll shut the hold, take off in 30 seconds, counting, and forcibly eject you - well, it can't be on Triton 'cause of Nep's radiation belt, but, damn it, back on Mars. Enough food, water and air, and I'll resupply every couple of months, but it'll be marooned on Mars for you - and no, I don't need a lady friend, who might take control of my UFO, even if you are an astronaut. I have higher, cosmic priorities.

Hatch closed, here we go. Can't say I didn't warn you ... Bye, folks. Whoooooooosh!

Ian Watson's most recent novel is The Waters of Destiny (with Andy West). The first volume is free to download from www.watersofdestiny.com. 